European Association for the Development of Renewable Energies, Environment and Power Quality

\title{
Dynamic Simulation of a Photovoltaic Installation
}

\author{
Ramos Hernanz, JA. ${ }^{1}$, Campayo Martín, J.J. ${ }^{1}$ Zamora Belver, I. ${ }^{2}$
}

Puelles Pérez, E. ${ }^{1}$, Motrico Gogeascoechea, JA. ${ }^{1}$, Sancho Sáiz, J ${ }^{3}$

${ }^{1}$ Department of Electrical Engineering

E.U.I., Vitoria-Gasteiz, University of the Basque Country

Nieves Cano, 1201006 Vitoria-Gasteiz (Spain)

Phone/Fax number: +0034 945014147, fax: +0034945013270

josean.ramos@ehu.es,jj.campayo@ehu.es, eduardo.puelles@ehu.es, joseba.motrico@ehu.es

${ }^{2}$ Department of Electrical Engineering

E.T.S.I., Bilbao, University of the Basque Country

Alameda Urquijo, s/n 48013 Bilbao (Spain)

Phone/Fax number: +0034 946014063, fax: +0034946014200 inmaculada.zamora@ehu.es

${ }^{3}$ Department of Nuclear Engineering and Fluid Mechanical

E.U.I., Vitoria-Gasteiz, University of the Basque Country

Nieves Cano, 1201006 Vitoria-Gasteiz (Spain)

Phone/Fax number: +0034 945013212, fax:+0034945013270 javier.sancho@ehu.es

\begin{abstract}
This paper presents the performance simulator of photovoltaic systems, developed through the software tool DigSilent PowerFactory. The study of this type of electrical generation is analyzed, modeling its capacities with advanced algorithms, from a totally flexible system and with unique concept of database.
\end{abstract}

This modelling work allows an easy and fast access to the analysis and design of photovoltaic systems, which facilitates a complete vision of system's behavior in different operation conditions.

In addition, a library of models of the main alternatives that can be included in a photovoltaic conversion system has been made.

\section{Key words}

Photovoltaic, DigSilent PowerFactory, Modelling, Simulation.

\section{Introduction}

Due to the opening of electrical markets and the necessity of alternatives to the generation of electrical power based on fossil fuels, a new interest in renewable sources has appeared. Among these systems, photovoltaic systems are expected to play a promising role in the generation of this kind of energy.
Nevertheless, photovoltaic power generation varies depending on weather conditions, season, and geographic location. These variations can cause problems like the voltage fluctuation and the frequency deviation. For this reasons, simulation models will facilitate the understanding of photovoltaic devices and their behavior when they are interconnected to the electrical network.

The objective of this paper is the development of a simulation work of different photovoltaic generation systems by means of a computer application. This tool based on mathematical models that allow to describe, explain and predict the system behavior in any operation condition, in order to obtain the maximum efficiency.

\section{Basic models}

The main elements that can be included in a system of photovoltaic conversion are: Batteries, Photovoltaic Modules, Loads DC and AC, Load Regulators, Inversors, Converters...

\section{A. Batteries}

Normally they have been considered as a simple element of storage of electrical energy. But its use in independent photovoltaic systems reinforces its protagonism, locating it in the center of the system; because they have to determine the point of work of the system and to feed the charges when radiation diminishes. For that, it is necessary to make 
a model that allows characterizing their answer to real conditions of work.

If you have a correct model of battery, the real problem can be approached: to anticipate the answer of the battery. In the short term, it is interesting to be able to know the evolution of voltage and current in tips of the battery, whereas in medium and length term it is needed to anticipate the evolution of the amount of energy that will store.

\section{B. Solar panel}

The solar panel is the power source of all photovoltaic installation. It is the result of a set of photovoltaic cells in series and parallel. In order to undertake its analysis, we begin from the study of a photovoltaic cell, main nucleus of the conversion of light to electrical current). Beginning from the electrical circuit that describes a cell, problems due to its association are analyzed.

\section{Load}

It is the component responsible to absorb this energy and transform it into work. The diversity, amount and complexity of the behavior of the loads that could be connected to a photovoltaic system make difficult to be modeled.

\section{Regulator}

It is the element to protect the battery against to risking situations as overloads and overdischarges. The theoretical formulation of the model can be simple, although it is necessary to consider the peculiar discontinuities of the model and the interperformance with the rest of the analyzed models.

\section{E. Inverter}

The inverter allows transforming the DC current to AC. A photovoltaic installation that incorporates an inverter can belong to two different situations, based on the characteristics of the alternating network:

- An isolated system, where the inverter is the element of the network and has to feed the set of loads.

- The inverter is connected to the public network, to which it sends the energy generated by the system.

The model must be able to include both situations.

\section{F. Converter}

The positioning of a converter between the panels and the batteries will improve the whole photovoltaic installation, allowing different controls from the system. Depending on the applied regulation, the panels will contribute to the maximum energy given to the system or the optimal energy for their operation, assuring an efficient charge of the battery.

\section{Simulation tool}

The software used for the modelling and simulation development has been DIgSILENT PowerFactory. It is an integrated tool of analysis of power systems, flexible and able to simulate any electrical element, with the only concept of handling a data base.

DIgSILENT has the ability to simulate load flow, RMS fluctuations and transient events in the same software environment. It provides models on a different level of detailing. It combines models for electromagnetic transient simulations of instantaneous values with models for electromechanical simulations of RMS values. This makes the models useful for studies of both (transient) grid fault and (longer-term) power quality and control issues.

DIgSILENT provides a comprehensive library of models of electrical components in power systems. The library includes models of generators, motors, controllers, dynamic loads and various passive network elements (lines, transformers, static loads and shunts).

\section{Elements of PowerFactory}

For the modelling of photovoltaic installations, from all the elements available in the library of PowerFactory, the following elements have been used:

\section{A. Source Current D.C.}

The ElmDci element is used to represent Sources Current DC. In this study, it has been used for modelling of the photovoltaic cell.

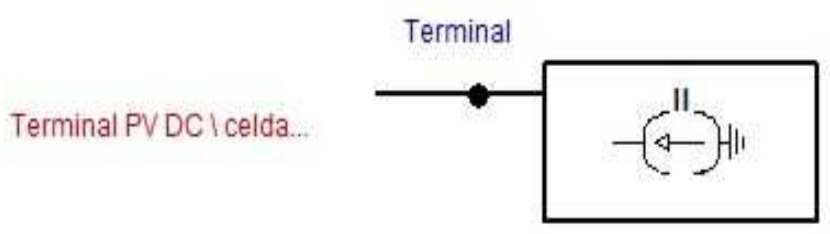

Fig. 1. Source Current D.C.

\section{B. Source Voltage D.C.}

In a first electrical approach, the battery can be considered as a source of real voltage. The source voltage, represents the circuit opened voltage between its terminals.

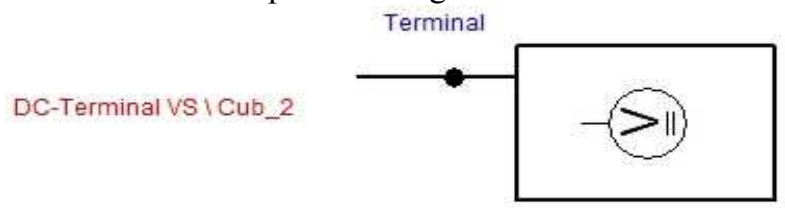

Fig. 2. Source Voltage D.C. 


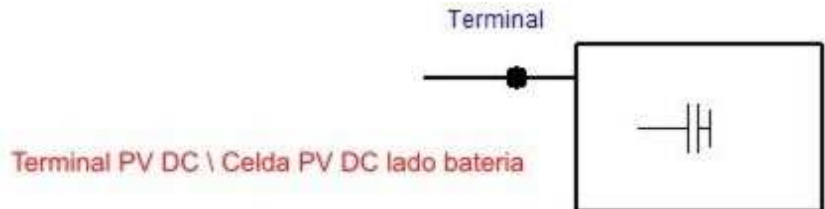

\section{Shunt/Filter}

The ElmShnt object is used to represent different types of derivative connections. From these models, the capacitor type is used.

Fig. 3. Shunt/Filter.

\section{PWM Converter}

Represents a self-commutated, voltage sourced AC/DC converter (capacitive DC circuit). This converter allows to transform the direct current system to alternating current system.

Fig. 4. PWM AC/DC Converter - 1 DC Connection

\section{E. PV Group (Static Generator)}

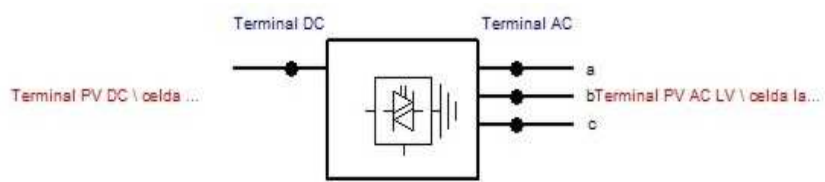

The Static Generator (ElmGenstat,) represents a generator, not rotating but static. From the different categories in which it is classified, for this study a Photovoltaic Generator chosen.

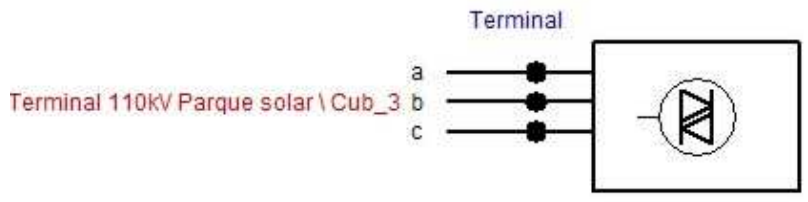

Fig. 5. Static Generator

\section{Models in PowerFactory}

The work presented in this paper has been mainly carried out for operation connected to the network.

The models this study is based on besides the own ones developed for the study, have used, as it basics, files already developed by the software. The models start from a simple model arriving to others of bigger complexity. In this work only some of the studied models are shown.

Thus the photovoltaic installations that have been modeled can be divided into three types:

- Installations whose main elements are: a source current D.C. (ElmDci), a source voltage D.C. (ElmDcu) and converter PWM/1 Connection DC (ElmVscmono).
- Installations composed by: a source current D.C. (ElmDci), a network of compensation filter/shunt (ElmShnt) and converter PWM/1 Connection DC (ElmVscmono).

- And the last type of installations are consisting mainly by one or several PV Group, represented by static generators (ElmGenstat). There are eight categories: Wind Generator, Photovoltaic, Other Renewable Generator, Cell Fuel, Other Static Generator, Terminal HVDC, Reactivate Power Compensation and Storage. From these options the Photovoltaic category has been chosen.

These types of installations can be part of much more complex models that include loads, generators, etc. Next, the modelling of these three options, in PowerFactory, is shown

\section{A. Model with Battery}

The photovoltaic generator consists of a source current D.C., connected to the AC system by a PWM converter. The storage system or the battery consists of a source voltage D.C also using a converter PWM for the connection with the AC terminal. The control way of the PWM converter in each use is different. The model is shown in figure 6 .

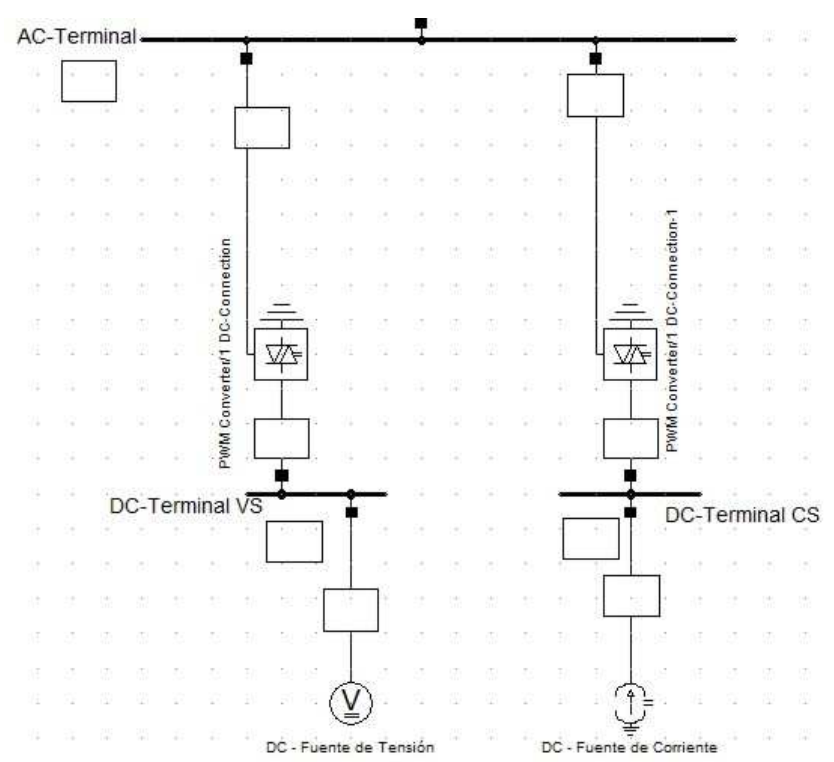

Fig. 6. Model with Battery

\section{B. Model with Shunt}

The photovoltaic generator is also a current source and feeds the load through a PWM converter. The PWM converter of the photovoltaic installation feeds from the generated energy available, independently of the load. The reactive energy of the photovoltaic generator is controlled to zero. Thus the generator must only control the voltage and the active energy to the network. (figure 7) 


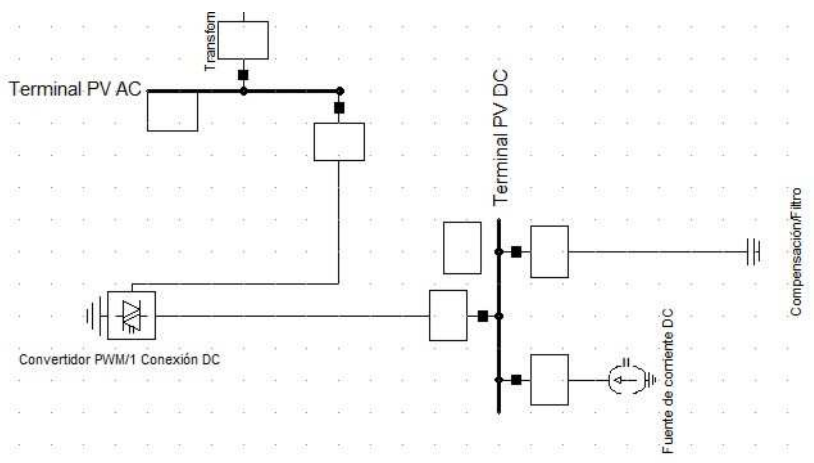

Fig. 7. Model with Shunt

\section{Model with Groupings PV}

The photovoltaic installation is composed by a group of static generators. (figure 8) In this case, the number of machines in parallel of each group, the rated Power and the Power Factor have to be defined. In the tab of the load flow, the reactive power can also be varied, among others things.

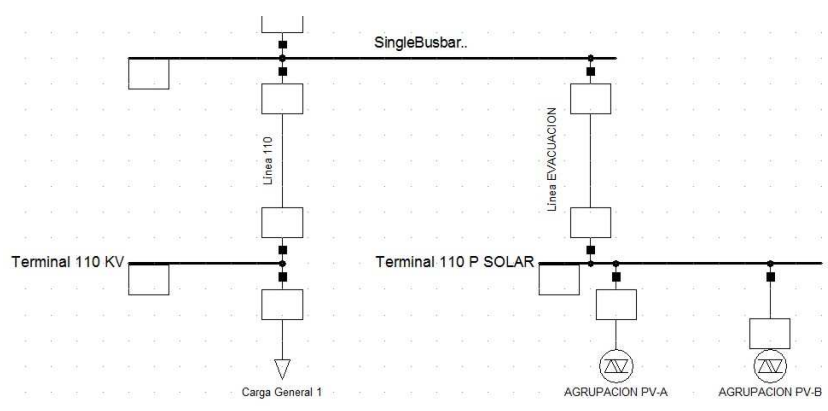

Fig. 8. Model with Groupings PV

\section{Working with PowerFactory}

Once the network has been designed, it is possible to make different calculations or tests, for example, load flow, short circuits, etc. These studies will be made independent of each other, in different Study Cases. Every Case stores the results, that could be checked or repeated afterwards. It looks as if a number of model variations would have been kept with the same data, in order to be changed when necessary.

In addition within any Study Case it is possible to have different Operation Scenarios. (figure 9) These scenes are different calculation conditions according to the same Case. It is possible to consider the continuous changes of the load, depending on the time. Also, it can be interesting to have a model working with data dependent on weather, the week, the station...

This is the case of the photovoltaic installations that are going to depend on the weather. The models admit the inclusion of these data from, for example, an Excel file, in which the measured profiles of production of the photovoltaic cell, of irradiation following the load, station... can be defined

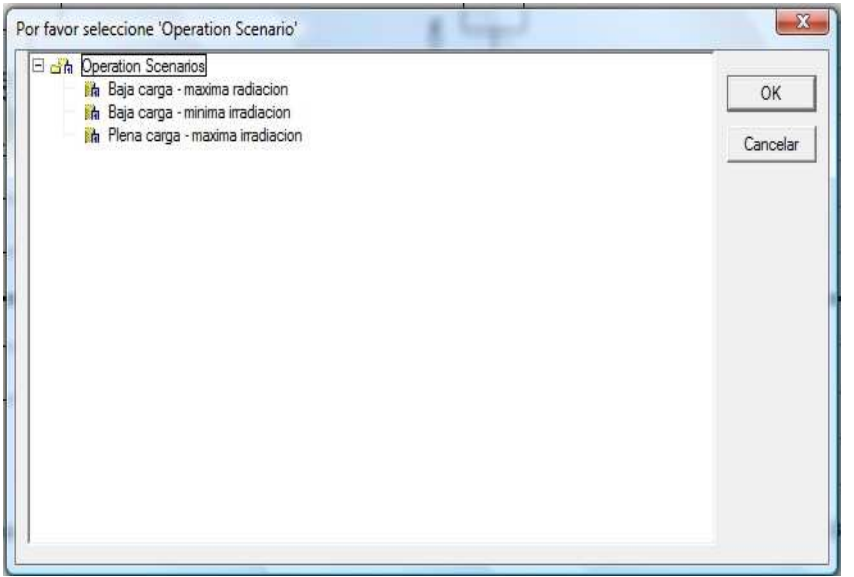

Fig. 9. Selection of Operation Scenarios

In the graphic windows of PowerFactory, the graphical results associated to active Study Case are shown. These windows or tabs can be of the following types:

- Grid, where will de defined the grid to model, and in which we will make the calculations. The scheme of the installation will be drawn to calculate or to simulate.

- Block/Frame diagrams, where the control of the elements will be represented by means of mathematical equations, example fig. 9.

- Virtual Instrument Panels. These elements are those that wil show the results graphically. There are many types, for example, graphs, bar charts, measurement elements, vectors diagram $\ldots$, example figures 10 and 11 .

- $\quad$ Single Line Graphic.

- Composite Net Element

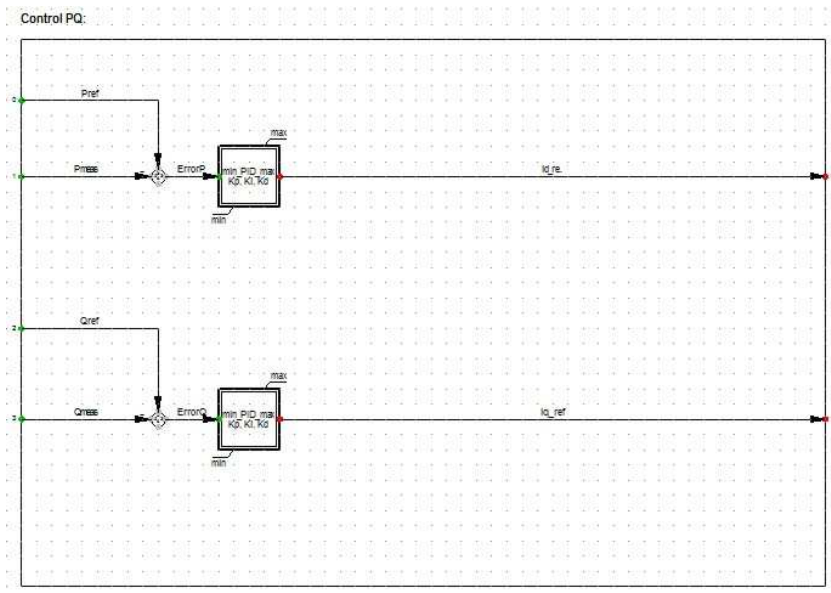

Fig. 10. Block/Frame diagram 


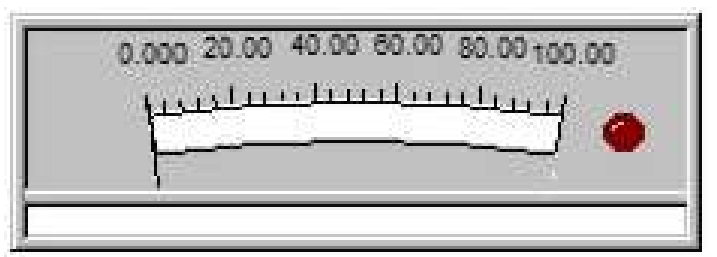

Fig. 11. Analogical measurement VI

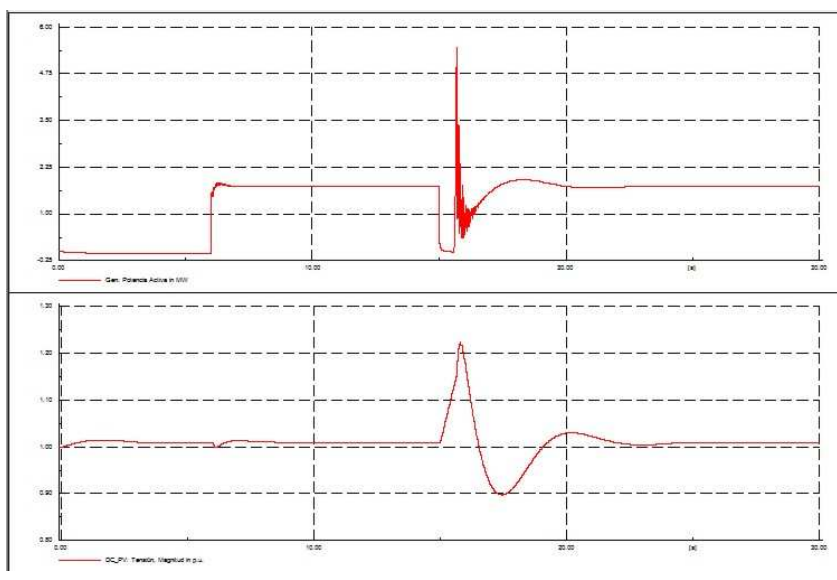

Fig. 12. Subplot/Diagramm VI

\section{Results}
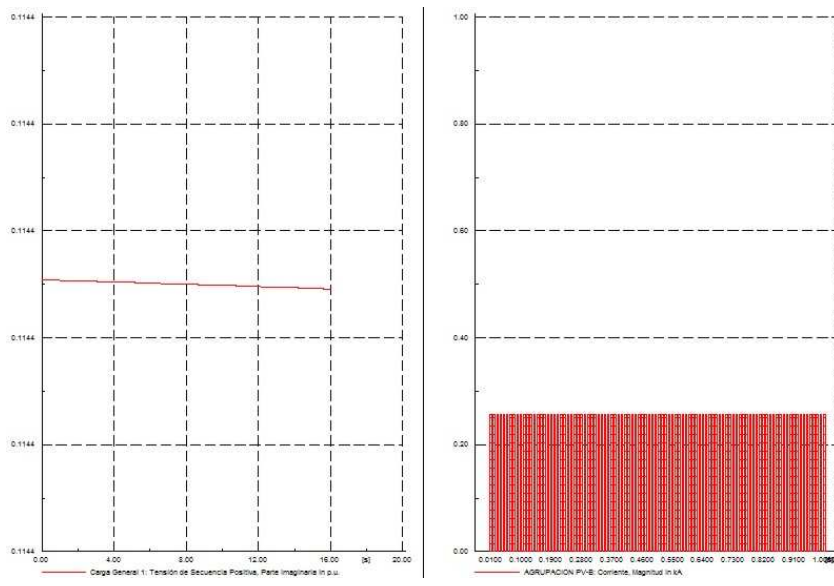

Fig. 13. Example of results Model with Battery
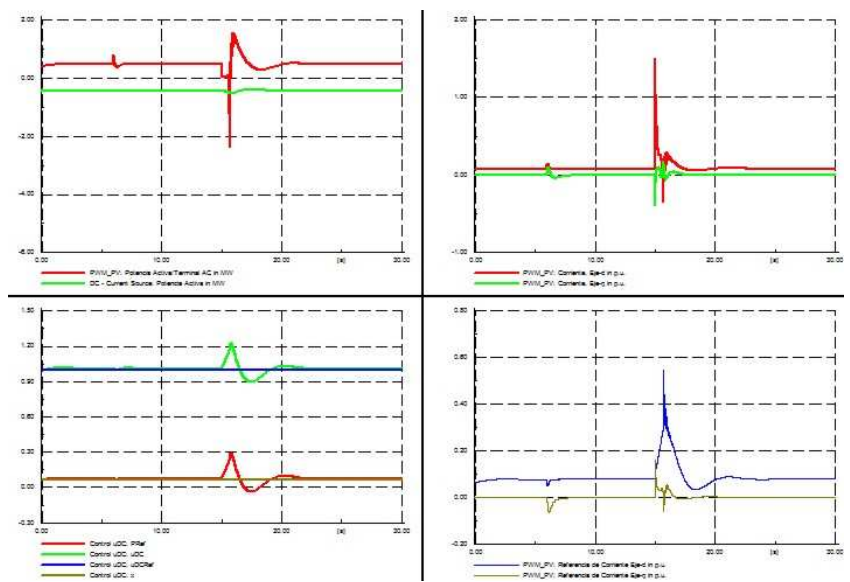

Fig. 14. Example of results Model with Shunt
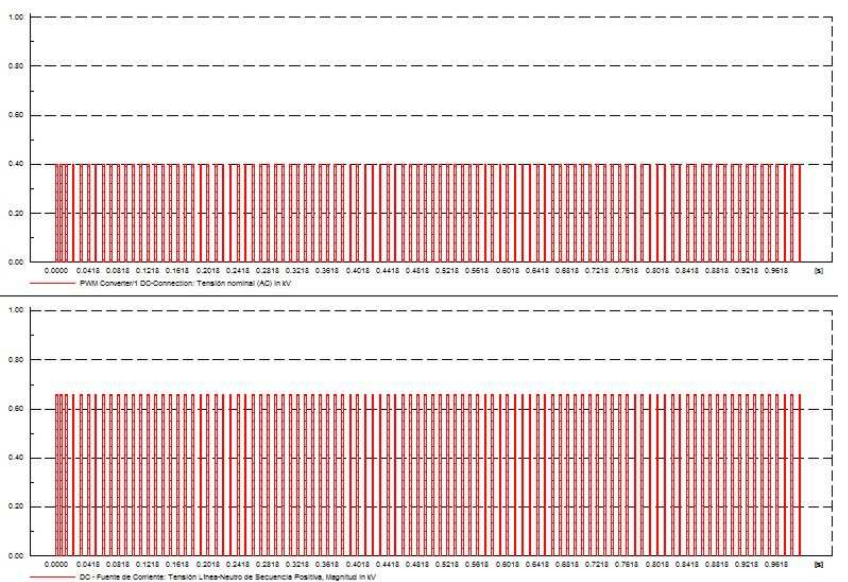

Fig. 15. Example of results Model with Groupings PV

\section{Conclusions}

The developed simulation model allows a safe and fast method to analysing and sizing a photovoltaic system, as well as the possibility of having a calculation tool power in different operation conditions, which shows a total clear vision of the complete system and its behavior.

The dynamic simulation of a photovoltaic system based on the software DIgSILENT PowerFactory presented in this paper allow a quick and easy access to the variations of currents and voltages in the nodes of the system. The detail of the simulation in terms of speed, types of analysis, graphical enviroments, robustness and the flexibility to analyze different topologies are evident advantages of the posibilities and functionality of this tool.

Nevertheless, the technical documentation of the elements of the library is small, which is a disadvantage.

\section{Acknowledgements}

The work presented in this paper has been supported by:

- Department of Education, Universities and Investigation, of the Basque Government.

- Vice chancellorship of Investigation of the UPV/EHU

\section{References}

[1] DIgSILENT GmbH, DIgSILENT Technical Documentation PowerFactory DSL Models, August 2006.

[2] DIgSILENT GmbH, DIgSILENT PowerFactory. User's Manual. DIgSILENT PowerFactory. Version 14.0 2008.

[3] DIgSILENT GmbH, PowerFactory Tutorial. DIgSILENT PowerFactory. Version 14.0. 2008

[4] Anca D. Hansen, Florin Iov, Poul Sørensen, Nicolaos Cutululis, Clemens Jauch, Frede Blaabjerg, "Dynamic wind turbine models in power system simulation tool DIgSILENT", Risø-R-1400(ed.2).

[5] Silvestre S., Castañer L. Guasch D, "Herramientas de Simulación para Sistemas Fotovoltaicos en Ingeniería", Formación Universitaria -Vol. $1 N^{o} 1-2008$. Pg 13-18

[6] Ryan C. Campbell, "A Circuit-based Photovoltaic Array Model for Power System Studies", Student Member, IEEE

[7] Perez R., Reed R., Hoff T., "Validation of a simplified PV simulation engine", 
[8] Guasch Murillo, Daniel Tesis Doctoral. "Modelado y análisis de sistemas fotovoltaicos". Abril 2003

[9] Sukamongkol Y., Chungpaibulpatana S.,. Ongsakul W, "A simulation model for predicting the performance of a solar photovoltaic system with alternating current loads".

[10] Sanz S., Bujedo L. A, Poncela M., Caballero P., Díaz J. I. "Simulación de instalaciones fotovoltaicas".

[11] Joycea A., Rodriguesa C., Mansob R. "Modelling a PV system" 